\title{
Cross-Cultural Sensitivity and Intensity of Interaction in Study Abroad: A Developmental Approach
}

\author{
Ariadna SÁnchez Hernández \\ Jaume I University \\ EMILIA Alonso-Marks \\ Ohio University
}

Received: 31 July 2016 / Accepted:18 February 2017

ISSN: $1697-7467$

\begin{abstract}
The present study examines second language (L2) learners' development of cross-cultural sensitivity (CCS) during study abroad (SA) programs, and how intensity of interaction with L2 speakers influences the reported gains. A group of US college students participating in a SA program in Mexico completed the Inventory of Cross-Cultural Sensitivity (ICCS) questionnaire (Cushner, 1986), a language contact questionnaire, and 10 weekly journal entries. The results revealed that learners did not significantly develop their CCS. Intensity of interaction, however, was enhanced during the semester, although it did not seem to affect CCS gains. Qualitative data provided insights into the reasons behind the reported development.
\end{abstract}

Keywords: study abroad; cross-cultural sensitivity; intensity of interaction; second language learners

Sensibilidad intercultural e intensidad de interacción durante estancias en el extranjero: un enfoque longitudinal

RESUMEN: Este estudio examina el desarrollo de la competencia intercultural de estudiantes de lenguas extranjeras durante estancias en el extranjero, y cómo la intensidad de interacción con hablantes nativos influye en el desarrollo intercultural. Un grupo de estudiantes estadounidenses en una estancia en México completaron el Inventario de Sensibilidad Intercultural (Cushner, 1986), un cuestionario de contacto y 10 entradas de diarios. Los resultados indicaron que los estudiantes no desarrollaron significativamente su competencia intercultural. Sin embargo, sí que aumentaron la intensidad de interacción, aunque esta no tuvo ningún efecto sobre las ganancias interculturales. Mediante datos cualitativos se obtuvieron detalles sobre la evolución observada.

Palabras clave: estudios en el extranjero; sensibilidad intercultural; intensidad de interacción; estudiantes de lenguas segundas

\section{INTRODUCTION}

In the present era of globalization, students need to acquire the necessary global knowledge to associate and interact with people from different cultures and origins. Braskamp, 
Braskamp and Merrill (2009), among others, explained that learners need to think and act so that they are able to live in a world where they know, work with and coexist with people from different cultural backgrounds, habits, customs, perspectives, religious opinions and aspirations. To satisfy this necessity, study abroad (SA) programs have become an essential tool that provides students with the chance to develop their cross-cultural sensitivity (CCS). As described in Alonso-Marks (2013), CCS is known to promote tolerance and respect for diversity, and it is a skill that can be learned with training and developed through intercultural experiences inside and outside the classroom.

Indeed, the design of SA programs is currently being reoriented towards the inclusion of intercultural cultural competence. The Global Opportunities Office at Ohio University, for instance, points out four different types of goals for studying abroad: (1) academic/intellectual, (2) professional, (3) personal, and (4) intercultural. Nevertheless, research on SA programs still tends to focus on linguistic outcomes, and the reported linguistic benefits have often overshadowed the cultural gains. Drawing from the acknowledgement that attaining CCS is a precursor of attaining an optimal level in a target language (TL) (Alonso-Marks, 2013), recent research calls for a focus not only on the linguistic but also on the non-linguistic outcomes of studying abroad (Pérez-Vidal, 2014). To address this concern, the present study examines the effectiveness of studying abroad for the development of CCS, and analyzes the effect of intensity of interaction upon the observed CCS gains.

\section{BACKGROUND RESEARCH}

Different definitions have been provided to cross-cultural sensitivity, in reference to learners' ability to understand, manage, and assimilate differences between the TL culture and their own (see Griffith, Wolfeld, Armon, Rios \& Lui, 2016, for a review of definitions and equivalent terms). It slightly differs from intercultural competence as CCS is "the ability to discriminate and experience relevant cultural differences" while intercultural competence is "the ability to think and act in interculturally appropriate ways" (Hammer, Bennett \& Wiseman, 2003:422). Nevertheless intercultural frameworks have been designed addressing both aspects, considering CCS as a precursor of intercultural competence. Some of these frameworks propose that CCS is a developing ability. Bennett (1993:24), for instance, refers to the process of acquiring CCS as "the construction of reality as increasingly capable of accommodating cultural difference that constitutes development." According to the author, 6 stages are involved in such developmental evolution: denial, defense, reversal, minimization, acceptance, adaptation, and integration. Other scholars view CCS as a componential construct that entails cognitive, affective and behavioral aspects. Byram's (1997:34) model of Intercultural Communicative Competence is an example. In this model, CCS involves 5 constructs: knowledge of the self and of the others; skills of interpreting and relating; skills of discovery and interaction; attitudes and openness towards others' values and beliefs; and critical cultural awareness. In a similar vein, Cushner (1986) proposes that CCS includes cultural integration, behavior, attitude towards others, intellectual interaction and empathy. Combining both the componential and the developmental approaches, Deardoff (2006) suggests that intercultural competence involves both internal aspects inherent in the individuals, 
and external elements related to the intercultural context; to acquire CCS, participants need to develop a set of skills, knowledge and attitudes particular to intercultural ability. What all frameworks of CCS share is the idea that CCS is a skill enhanced by a combination of first-hand experience of cultural diversity and of critical reflection (Vande Berg, Paige \& Lou, 2012).

SA programs have typically been referred to as the optimal context for culture learning (for a review, see Mitchell, Tracy-Ventura \& McManus, 2017). This is not surprising, given the vast amount of opportunities the context offers to sojourners for interaction with L2 users of varied origins and in different situations. In fact, there is a burgeoning of studies addressing intercultural development during SA that have revealed positive gains in CCS. These studies have commonly compared intercultural competence of a group of students abroad with that of their peers at home $(\mathrm{AH})$, reporting that any type of sojourn abroad, no matter how short it is, is more beneficial for the acquisition of CCS than the AH learning context (Chieffo \& Griffits, 2004; Williams, 2005). Additionally, a few longitudinal studies have traced the development of CCS over time, finding positive gains in CCS during one year of study abroad (Medina-López-Portillo (2004), one semester (Allen, Dristas \& Mills, 2006; Paige, Cohen \& Shively, 2015; Watson, \& Wolfel, 2015; Williams, 2005) and even during short-term SA programs (Anderson, Lawton, Rexeisen \& Hubbard, 2006; Chieffo \& Griffits, 2004; Czerwionka, Artamonova \& Barbosa, 2015; Jackson, 2009; Martinsen, 2011). Moreover, some investigations have revealed an overall improvement in CCS levels, but different developmental paths when exploring intercultural subscales (Anderson et al., 2006; Jackson, 2009; Paige et al., 2015; Taguchi, Xiao \& Li, 2017). These studies have commonly through Hammer and Bennett's (2002) Intercultural Development Inventory (IDI), Kelley and Meyer's (1999) Cross-Cultural Adaptability Inventory (CCAI) or through Cushner's (1986) Inventory of Cross-Cultural Sensitivity (ICCS).

Nevertheless, unsuccessful or limited CCS development during SA has also been documented in the literature, challenging the assumption that mere exposure to the TL community is enough for gaining critical understanding of cultural differences (Bloom \& Miranda, 2015; Goldoni, 2013; Kinginger, 2013;0, Bernans \& Gardner, 2002; Salisbury, An \& Pascarella, 2013; Schartner, 2016; Vande Berg, Connor-Linton \& Paige, 2009; Wilkinson, 2000). Bloom and Miranda (2015), for instance, explored the reasons why a group of 12 US students during a summer program in Spain did not improve their CCS, finding a significant role of previous intercultural contact. That is, those students who had already been exposed to intercultural experiences did not make significant gains in intercultural competence during the sojourn. Similar findings were reported by Schartner (2016), who found a decrease in cultural empathy and open mindedness by 223 students over a year of study in the UK. Semi-structured interviews to the participants revealed some potential limitations of CCS development: the fact that some students started the SA program with high levels of CCS, disappointment towards intercultural experiences, and encountering of barriers to communication.

Despite the inconclusive and mixed findings on the benefits of SA programs for the development of CCS, very few studies have investigated what factors determine CCS gains (Martinsen, 2011; Ramirez, 2016; Williams, 2005). Addressing this research gap seems an urgent point in the agenda considering that higher education institutions are placing more and more importance on the development of intercultural competence during SA. Drawing from the available empirical evidence, two main factors seem to predict CCS during SA: length 
of stay (Engle \& Engle, 2004; Medina-López-Portillo, 2004) and intensity of interaction (Martinsen, 2011). As for first factor, Medina-López-Portillo (2004) conducted a mixedmethod study to explore CCS development by 28 US students in two language programs in Mexico: one was 7 weeks long, and the other one was 16 weeks long. Quantitative findings from administration of the IDI (Hammer \& Bennett, 2002) revealed that learners in the semester-long program improved their intercultural sensitivity greater than those enrolled in the short-term program. Additionally, qualitative data showed that students in the longer program exhibited a more in-depth knowledge and understanding of the Mexican culture. They showed a critical perspective towards cultural differences, and towards the Mexican political system, whereas comments by students in the shorter sojourn were limited to external and behavioral aspects such as shopping and food.

Regarding intensity of interaction, a few studies have pointed out the importance of quantity, nature and diversity of interactions with members of the TL community for the development of CCS (Twombly, 1995; Wilkinson, 1998). Such influential relationship does not surprise, given that direct contact with members of the host community brings about first-hand experience with cultural differences. However, very few studies have adressed the direct relationship between amount of interaction with native speakers and CCS gains (Martinsen, 2011; Watson \& Wolfel, 2015). Martinsen (2011), in this regard, explored the effect of different SA factors on the development of CSS by 45 US students participating in a 6-week SA program in Argentina. CCS was measured through the ICCS (Cushner, 1986), while intensity of interaction was assessed through a Language Contact Profile (Freed, Dewey \& Segalowitz, 2004). Findings revealed that during this short stay, learners increased their CCS, and the reported gains were strongly influenced by amount of time spent with members of the host community, but they were unrelated to the other explored factors (oral proficiency in Spanish, motivation and relationship with their host families). Such statistically-significant and strong influence of intensity of interaction on CCS suggests the need for more research on this association.

To sum up, the available mixed findings on the benefits of SA for the development of CCS point to the complexity of the context for second language learners, who, in addition to learning a new language, have to face the multiple challenges involved in the process of adapting to a new and unknown place while being expected to interact with people of different cultural backgrounds. Given the scarcity of research addressing what factors determine the development of CCS by international college students, the present study sheds some light on the above mentioned complexity by exploring the role of intensity of interaction on CCS gains during a semester of study abroad.

\section{3. Мethod}

\subsection{Research questions}

Drawing from the background research reviewed above, the present study will be a contribution to the ongoing dialog in the discipline about how students develop cross-cultural sensitivity and intensity of interaction, and how the latter affects the former, during study abroad. It will seek to answer three basic questions: 
Does study abroad make a difference in the development of cross-cultural sensitivity? Is there an increase in intensity of interaction during the study abroad period?

Does intensity of interaction play a role in the development of cross-cultural sensitivity?

\subsection{Participants}

Eight students at a Midwestern university in the U.S.A. participated in the study. They were enrolled in a 14-week study abroad program in Merida, Mexico, which was administered by staff from the students' home institution, and the host institution. All participants were native English speakers between the ages of 18 and 24, with an average age of 20.5. Additionally, the 8 had a minimum of two years of university-level Spanish; indeed, many had already taken upper-division courses or were about to register in upper division courses. The students' home institution selected learners to participate in the program based on a grade point average, a personal essay, and recommendations from faculty. Participating in a minimum 6-to-14-week study abroad program in a Spanish-speaking country is a requirement for all Spanish majors.

\subsection{The study abroad program}

Prior to departure, students were required to attend four pre-departure orientation meetings in which they received information intended to prepare them for their time abroad in terms of the curriculum, the extra-curricular activities, the host institution, the facilities, the city, other program components, and the cultural differences they would experience. During their time abroad, individual students were placed with a Mexican host family selected by the host institution in consultation with the host university. The program offered an ample selection of upper division courses in language, linguistics, literature, and civilization and culture. Students were required to take 12 credit hours and some took as many as 16.

\subsection{Instruments and procedure}

This study involves a mixed-method approach. Quantitative data was obtained following a pretest-posttest design to monitor students' progress during the semester-long immersion program. Additionally, qualitative information provided details about the nature of the sociocultural experiences and the patterns of interaction participants held in the host country.

\subsubsection{Background questionnaire}

The background questionnaire collected data about students' background in general with a special focus on their knowledge of languages other than English and Spanish, their level of Spanish and their previous contact with the Spanish culture. Students provided demographic information such as name, age and gender. Then, they indicated level of proficiency in Spanish and of other languages they knew. Finally, they provided information about previous experience in Spanish-speaking countries. The background questionnaire was administered in a pre-departure meeting, one week before going abroad. 


\subsubsection{Language Contact Profile (adapted from Freed, Dewey \& Segalowitz, 2004)}

The purpose of the Language Contact Profile (LCP) survey was to assess the amount of contact in the L2 (Spanish, in this case) in different contexts (e.g. the classroom, with friends, with strangers). The LCP consists of 10 items in which participants are asked to indicate how many days per week and how many hours per day they spend using the L2 in different situations. The questionnaire used in this study is a modified version of Freed, Dewey \& Segalowitz' (2004) Language Contact Profile. The instrument was administered during the second week of the program (pre-test), and again during the last week of the program (post-test) to measure students' level of involvement using the L2 in authentic situations.

\subsubsection{Inventory of Cross-Cultural Sensitivity (ICCS) (Cushner, 1986)}

The ICCS consists of 32 items corresponding to five subscales: cultural integration, behavioral scale, intellectual interaction, attitude towards others and empathy scale. The items are presented on a 7-point Likert scale ranging from 1 (strongly disagree) to 7 (strongly agree). Its reliability and validity has been reported in a number of previous studies (Mahon \& Cushner, 2014; Martinsen, 2011). The ICCS was administered at week 2 and week 10 of the program to measure students' potential growth in cross-cultural sensitivity.

\subsubsection{Weekly Journals}

Participants also completed 10 weekly journal entries reflecting on different aspects pertaining to their experience with foreigners, and with cultural differences at home and while in Mexico. In particular, they collected information about the nature of interaction with native speakers of Spanish and with speakers of other languages, cultural integration, behavioral adaptation, intellectual interaction, attitude towards others and empathy. Journal lengths were 1 to 2 pages, Times New Roman 12, double-spaced, and they were coded for indicators of recurring themes.

\section{RESUltS AND DISCUSSION}

In order to address the first research question, Does study abroad make a difference in the development of cross-cultural sensitivity?, pre-test and post-test CCS data, and information about the five subscales included in the ICCS were compared by means of a series of Wilcoxon Signed-Ranks tests. This non-parametric test was chosen given the small amount of participants. Table 1 displays pre-test and post-test means, standard deviations, differences -which indicate gains, - and results from the Wilcoxon Signed-Ranks tests for overall CCS data and for ratios of each of the subscales. 
Ariadna Sánchez Hernández and Emilia Alonso-Marks $\quad$ Cross-Cultural Sensitivity and Intensity...

Table 1. Pre-test and post-test means, standard deviations, differences and Wilcoxon test results in cross-cultural sensitivity

\begin{tabular}{|c|c|c|c|c|c|c|c|c|c|}
\hline & \multirow[b]{2}{*}{$\mathrm{n}$} & \multicolumn{2}{|c|}{ Pre-test } & \multicolumn{2}{|c|}{ Post-test } & \multirow[b]{2}{*}{ Difference } & \multirow[b]{2}{*}{$\begin{array}{c}\text { Difference } \\
(\%)\end{array}$} & \multirow[b]{2}{*}{$Z$} & \multirow[b]{2}{*}{ Sig. } \\
\hline & & Mean & $\mathrm{SD}$ & Mean & SD & & & & \\
\hline Overall CCS & 8 & 174.87 & 22.89 & 175.62 & 18.46 & $0.75^{*}$ & 0.33 & -0.14 & .888 \\
\hline $\begin{array}{l}\text { - Attitude towards } \\
\text { others }\end{array}$ & 8 & 32.38 & 1.69 & 33.50 & 1.20 & $1.12 *$ & 3.2 & -1.45 & .147 \\
\hline - Behavioral scale & 8 & 30.25 & 2.25 & 28.75 & 2.49 & $-1.5^{*}$ & -3.57 & -1.38 & .168 \\
\hline $\begin{array}{l}\text { - Cultural } \\
\text { integration }\end{array}$ & 8 & 46.37 & 13.16 & 50.75 & 11.91 & $4.37 *$ & 6.24 & -1.12 & .262 \\
\hline - Empathy & 8 & 28.75 & 4.40 & 28.5 & 4.24 & $-0.25 *$ & -0.71 & -0.51 & .610 \\
\hline $\begin{array}{c}\text { - Intellectual } \\
\text { interaction }\end{array}$ & 8 & 35.37 & 6.34 & 34.5 & 5.13 & $-0.87^{*}$ & -2.07 & -0.94 & .348 \\
\hline
\end{tabular}

Note: ${ }^{*} p>0.1$ (Wilcoxon Signed-Ranks tests)

Quantitative results from the Wilcoxon Signed-Ranks tests showed that there were no significant differences between the pretest and the posttest in overall CCS ratios $[Z=-0.14$; $p>0.1]$. However, although the results were not significant, there was a slight improvement in CCS (difference $=0.33 \%$ ), so we can say that there is a trend of slight improvement. More participants will be needed in order to obtain statistically significant corroboration of this trend. These results are in consonance with previous longitudinal studies that have reported a limited or non-significant improvement in CCS aspects during SA programs (Bloom \& Miranda, 2015; Goldoni, 2013; Kinginger, 2013; Masgoret, Bernans \& Gardner, 2000; Salisbury, An \& Pascarella, 2013; Schartner, 2016; Van de Berg, Onnor-Linton \& Paige, 2009; Wilkinson, 2000). With regards to the Cross-cultural Sensitivity Subscales, results also revealed no significant differences between the pretest and the posttest. Nevertheless, a trend emerged, whereby two of the subscales, Attitude toward others, and Cultural integration, progressed from the pretest to the posttest $(3.20 \% ; 6.24 \%$ respectively), while the other subscales did not exhibit the same development. These results imply that the SA experience enhanced students' attitudes towards the Mexican community as well as their integration in their culture. However, students did not substantially improve their CCS, as evident in a decrease in behavioral aspects, their cross-cultural empathy and their intellectual interaction with the Mexican community.

Qualitative results seem to support the findings from the quantitative data. No statistically significant results are reflected in the fact that $50 \%$ of the sample (that is, 4 participants) exhibited positive CCS gains, while the other $50 \%$ showed negative gains. To obtain insights into their SA experiences, learners' responses to weekly diaries were examined. Students provided simplified, superficial observations of Merida, Mexico, and their SA experience, which seemed not to have contributed to challenge their in-coming perspectives. Comments 
displayed a pre-disposed concern toward personal safety; mentioned a disparity between the distribution of wealth (privileged and underprivileged communities); accused a patriarchal, male-dominant society; mentioned stereotypical features such as openness, loudness, and unpunctuality; and invalidated their stay abroad as they felt the program focused on doing "touristy" extra-curricular activities as opposed to more authentic, "real" Mexican activities. Students seemed to have applied the lens of apparent US cultural superiority to view and judge their time abroad.

With regards to the second research question, Is there an increase in intensity of interaction during the SA period?, a further Wilcoxon Signed-Ranks test revealed a significant increase in intensity of interaction between the pretest $(M=7.01 ; S D=6.60)$ and the posttest $(M=10.28 ; S D=6.34), Z=-1.68, p=.09$. This means that learners did improve their amount and quality of contact with native speakers of Spanish.

Not surprisingly, qualitative results support quantitative findings. Students were aware that they needed to look for opportunities to interact in Spanish. Over the course of their stay, they realized that they were gaining in fluency and confidence. Students valued the fact that community members were not modifying their speech to make it more comprehensible for them. They also recognized that the main source of intensity of interaction came from their home stay, their host families; and the second, their instructors. They felt that teachers enhanced the quantity and quality of their interactions.

For the third research question, Does target language exposure play a role in the development of cross-cultural sensitivity?, results from a simple linear regression analysis indicated that intensity of interaction did not determine $\operatorname{CCS}[\mathrm{F}(1,6)=1.165, p=0.322)$. In order to explore further relationships between this variable, a correlation between the two types of change - intensity of interaction and cross-cultural sensitivity - and between the pretest and the posttest indicated a non-significant difference, $r(6)=-4.03, p=.322$. Hence, findings of this study reveal that a higher degree of intensity of interaction does not seem to guarantee greater gains in CCS. These findings do not support those reported by Martinsen (2011), who observed a strong influence of intensity of interaction on the development of CCS. Drawing from the qualitative analysis, we hypothesize that contact with members of the host community may have not been relevant enough for students to maximize their experience abroad.

\section{Conclusions}

The results of the present study question the potential benefits of SA programs in two parameters, namely, CCS and intensity of interaction. On the one hand, SA programs do not seem to have any significant impact on students' development of CCS. On the other, intensity of interaction, which has traditionally been considered a key measure of success in the context of study abroad by itself, does not seem to be enough to document students' benefits. We hypothesize that the development of CCS may be a matter of learners' individual differences rather than the SA experience itself and the opportunities for interaction available.

One of the main limitations of the present study was the scarcity in the number of participants. This may be a reflection of current trends in SA programs in the study site. The gradual decline in student participation in SA programs in the analyzed public institution is 
due mainly to economic constraints (program costs), curricular inflexibility (certain courses are only offered in sequence), and program length (with the switch to semesters at the home institution). However, we addressed this limitation by implementing a mixed-method approach that combined quantitative and qualitative information. Future studies should not only include a larger pool of participants, but a variety of SA programs and settings. We suggest replicating the study to document linguistic outcomes, and also to monitor the development of CCS. In this sense, future studies should include a pretest, a posttest, and also a delayed posttest in order to measure long-term benefits of the participants' experience abroad. It would be interesting to analyze the effects of pre-departure orientations on students' development of CCS, so that a more accurate comparison could be made between the results of the pretest and the posttest.

Another suggestion would be to compare the two parameters - cross-cultural sensitivity and intensity of interaction - with linguistic gains. We suspect there may be a correlation between amount and quality of intensity of interaction with linguistic outcomes and gains. However, how linguistic gains are facilitated through greater CCS is yet another area of inquiry to be pursued at length and in depth.

The findings of the present study provide valuable practical implications for students going abroad, teachers, and program organizers. Students need to take on the responsibility of practicing the language while taking advantage of all the opportunities afforded to them. Moreover, study abroad directors and program organizers need to make note of important ideas and strategies advanced by the qualitative data of our study. Maximizing authentic student interactions with host family members, teachers, and other members of the host community are crucial to boost students' cultural integration, attitudes toward others, as well as linguistic confidence and fluency. Hence, assessing the effectiveness of SA programs should be a priority in order to help students develop the skills necessary to deal effectively with cultural differences while immersed abroad. These findings reveal the need for future research on factors affecting student cultural benefits and outcomes within the SA context.

\section{REFERENCES}

Allen, H. W., Dristas, V. and Mills, N. (2006). Cultural learning outcomes and summer study abroad. In M. Mantero (ed.), Identity and second language learning: culture, inquiry, and dialogic activity in educational contexts (pp. 189-215). Charlotte, NC: Information Age Publishing.

Alonso-Marks, E. (2013). Assessing the impact of a short-term study abroad program on gains in cross-cultural sensitivity. La Lingüistica aplicada en la era de la globalización [Applied Linguistics in the Age of Globalization]. In A. Llanes-Baró, L. Astrid Ciro, L. Gallego Balsà and R.M. Mateu Serra (eds.). Lleida: Edicions de la Universitat de Lleida, Spain.

Anderson, P., Lawton, L., Rexeisen, R. and Hubbard, A. (2006). Short-term study abroad and intercultural sensitivity: A pilot study. International Journal of Intercultural Relations, 30: 457-69.

Bennett, M. J. (1993). Towards ethnorelativism: A developmental model of intercultural sensitivity. In R. M. Paige (ed.), Education for the intercultural experience (pp. 21-71). Yarmouth, ME: Intercultural Press. 
Bloom, M. and Miranda, A. (2015) Intercultural sensitivity through short-term study abroad. Language and Intercultural Communication, 15(4): 567-580.

Braskamp, L. A., Braskamp, D. C. and Merrill, K. C. (2009). Assessing progress in global learning and development of students with education abroad experiences. Frontiers: The Interdisciplinary Journal of Study Abroad, 18: 101-118.

Byram, M. (1997). Teaching and Assessing Intercultural Communicative Competence. Clevedon: Multilingual Matters.

Czerwionka, L., Artamonova, T. and Barbosa, M. (2015). Intercultural knowledge development: Evidence from student interviews during short-term study abroad. International Journal of Intercultural Relations, 49: 80-99.

Chieffo, L., and Griffiths, L. (2004). Large-scale assessment of student attitudes after a shortterm study abroad program. Frontiers: The Interdisciplinary Journal of Study Abroad, 10: $165-177$.

Cushner, K. (1986). Human Diversity in Action: Developing Multicultural Competencies for the Classroom. New York: McGraw-Hill.

Deardorff, D. K. (2006). Assessing intercultural competence in study abroad students. In M. Byram \& A. Feng (eds), Living and studying abroad: Research and practice (Vol. 12, pp. 232-256). Clevedon: Multilingual Matters.

Engle, L. and Engle, J. (2004). Assessing language acquisition and intercultural sensitivity development in relation to study abroad program design. Frontiers: The Interdisciplinary Journal of Study Abroad, 10: 219-236.

Freed, B., Dewey, D. and Segalowitz, N. (2004). The Language Contact Profile. Studies in Second Language Acquisition, 26: 349-56.

Goldoni, F. (2013). Students' immersion experiences in study abroad. Foreign Language Annals, 46(3): 359-376.

Griffith, R., Wolfeld, L., Armon, B., Rios, J. and Liu, O. L. (2016). Assessing intercultural competence in higher education: Existing research and future directions. Educational Testing Service Research Report No. RR-16-25. Wiley Online Library.

Hammer, M. R. and Bennett, M. J. (2002). The Intercultural Development Inventory (IDI) Manual. Portland, OR: Intercultural Communication Institute.

Hammer, M. R., Bennett, M. J. and Wiseman, R. (2003). Measuring intercultural sensitivity: The intercultural development inventory. International Journal of Intercultural Relations, 27: 421-443.

Jackson, J. (2009). Intercultural Learning on Short-Term Sojourns. Intercultural Education, 20(12): $59-71$.

Kelley, C., and Meyers, J. (1999). The cross-cultural adaptability inventory. In S. M. Fowler \& M. G. Mumford (eds.), Intercultural Sourcebook: Cross-cultural Training Methods (vol. 2, pp. 53-60). Yarmouth, MA: Intercultural Press.

Kinginger, C. (2013). Social and cultural aspects of language learning in study abroad. Amsterdam/New York: John Benjamins.

Martinsen, R. (2011). Predicting changes in cultural sensitivity among students of Spanish during short-term study abroad. Hispania, 94: 121-141.

Masgoret, A., Bernaus, M., and Gardner, R. C. (2000). A study of cross-cultural adaptation by English-speaking sojourners in Spain. Foreign Language Annals, 33(5): 548-558.

Medina-López-Portillo, A. (2004). Intercultural learning assessment: The link between program duration and the development of intercultural sensitivity. Frontiers: The Interdisciplinary Journal of Study Abroad, 10: 179-99. 
Mitchell, R., Tracy-Ventura, N., and McManus, K. (2017). Identity, social relationships and language learning during residence abroad. Routledge

Paige, R. M., Cohen, A. D. and Shively, R. L. (2004). Assessing the impact of a strategies-based curriculum on language and culture learning abroad. Frontiers: The Interdisciplinary Journal of Study Abroad, 10: 253-276.

Pérez-Vidal, C. (Ed.) (2014). Language acquisition in study abroad and formal instruction contexts. Amsterdam/Philadelphia: John Benjamins Publishing Company.

Ramirez, E. (2016). Impact on intercultural competence when studying abroad and the moderating role of personality. Journal of Teaching in International Business, 27(2-3): 88-105.

Salisbury, M, An, B. and Pascarella, E. (2013). The effect of study abroad on intercultural competence among undergraduate college students. Journal of Student Affairs Research and Practice, 50(1): 1-20.

Schartner, A. (2016). The effect of study abroad on intercultural competence: a longitudinal case study of international postgraduate students at a British university. Journal of Multilingual and Multicultural Development, 27(4): 402-418.

Twombly, S. (1995). Piropos and friendships: Gender and culture clash in study abroad. The Interdisciplinary Journal of Study Abroad, 1: 1-27.

Vande Berg, M., Paige, R. M., and Lou, K. (eds.) (2012). Student learning abroad: What our students are learning, what they're not, and what we can do about it. Sterling, VA: Stylus.

Vande Berg, M., Connor-Linton, J., and Paige, M. R. (2009). The Georgetown Consortium Project: Interventions for student learning abroad. Frontiers: The Interdisciplinary Journal of Study Abroad, 18: 1-75.

Watson, J. and Wolfel, R. (2015). The intersection of language and culture in study abroad: Assessment and analysis of study abroad outcomes. Frontiers: The Interdisciplinary Journal of Study Abroad, 25: 57-72.

Wilkinson, S. (1998). On the nature of immersion during study abroad: Some participant perspectives. Frontiers: The Interdisciplinary Journal of Study Abroad, 4: 121-138.

Wilkinson, S. (2000). Emerging questions about study abroad. ADFL Bulletin, 32: 36-41.

Williams, T. R. (2005). Exploring the impact of study abroad on students' intercultural communication skills: Adaptability and sensitivity. Journal of Studies in International Education, 9: $356-371$. 